\title{
Dynamic Occlusion of Distal Ventriculoperitoneal Shunt Catheter after Infusion Port Placement: A New Shunt Malfunction
}

\author{
Lacey M. Carter ${ }^{1}$ Camille K. Milton ${ }^{1}{ }^{10}$ Kyle P. O'Connor ${ }^{1}$ Arpan R. Chakraborty ${ }^{10}$ \\ Tressie M. Stephens ${ }^{1}$ Chad A. Glenn ${ }^{1}$ \\ ${ }^{1}$ Department of Neurosurgery, The University of Oklahoma Health \\ Sciences Center, Oklahoma City, Oklahoma, United States \\ Address for correspondence Chad A. Glenn, MD, Department of \\ Neurosurgery, The University of Oklahoma Health Sciences Center, \\ $1000 \mathrm{~N}$ Lincoln Boulevard, Suite 4000, Oklahoma City, OK 73104- \\ J Neurol Surg Rep 2021;82:e17-e20. \\ 5410, United States (e-mail: chad-glenn@ouhsc.edu).
}

\begin{abstract}
Shunt failure requiring reintervention remains a common complication of hydrocephalus treatment. Here, we report a novel cause of mechanical shunt obstruction in an adult patient: position-dependent intermittent occlusion via an infusion port catheter. A 51-year-old woman with a grade II oligodendroglioma presented in a delayed fashion following surgery with a pseudomeningocele. She underwent ventriculoperitoneal shunt placement due to communicating hydrocephalus, resolving her pseudomeningocele. Shortly thereafter, she underwent placement of a subclavian infusion port at an outside institution. Her pseudomeningocele returned. Imaging demonstrated close proximity of her port catheter to the shunt catheter overlying the clavicle. Her shunt was tapped demonstrating a patent ventricular catheter with normal pressure. She underwent shunt exploration after her pseudomeningocele did not respond to valve adjustment. Intraoperative manometry demonstrated head position-dependent distal

Keywords

- pseudomeningocele

- ventriculoperitoneal shunt

- shunt malfunction

- mechanical obstruction catheter obstruction. Repeat manometry following distal catheter revision demonstrated normal runoff independent of position. Her pseudomeningocele was resolved on follow-up. To our knowledge, this is the only reported case of intermittent, positiondependent distal catheter obstruction. Shunted patients with concern for malfunction following subclavian infusion port placement should be evaluated for possible dynamic obstruction of their distal catheter when the two catheters are in close proximity along the clavicle.
\end{abstract}

Hydrocephalus is a commonly encountered neurosurgical condition with a significant health care burden. The annual impact of pediatric hydrocephalus alone in the United States is 38,200 to 39,900 hospital admissions and approximately $\$ 2$ billion in hospital charges. ${ }^{1}$ While the overall prevalence of pediatric hydrocephalus remains stable, the rates of obstructive hydrocephalus have increased over the years, likely due to improved survival of preterm infants. ${ }^{2,3}$ Management approaches to adult hydrocephalus have largely been extrapolated from clinical studies of the pediatric received

June 10, 2020

accepted

November 17, 2020
DOI https://doi.org/

$10.1055 / \mathrm{s}-0041-1726274$. ISSN 2193-6358.

\footnotetext{
(C) 2021. The Author(s).

This is an open access article published by Thieme under the terms of the Creative Commons Attribution-NonDerivative-NonCommercial-License, permitting copying and reproduction so long as the original work is given appropriate credit. Contents may not be used for commercial purposes, or adapted, remixed, transformed or built upon. (https://creativecommons.org/ licenses/by-nc-nd/4.0/) Georg Thieme Verlag KG, Rüdigerstraße 14, 70469 Stuttgart, Germany
} 
hydrocephalus population. ${ }^{4}$ Causes of adult-onset acquired noncommunicating hydrocephalus include tumor mass effect, infection, or other mass lesions. ${ }^{4}$ Shunt failure requiring reintervention is a common complication of hydrocephalus treatment. ${ }^{4}$ Prospective studies have demonstrated that $40 \%$ of patients experience shunt failure requiring revision within the first 2 years of placement. ${ }^{5}$ We present a unique case in which the placement of an infusion port after ventriculoperitoneal shunt (VPS) insertion in an adult patient led to intermittent, dynamic distal catheter occlusion dependent on the patient's head and neck position.

\section{Case Report}

\section{History}

A 51-year-old woman with a history of right frontal grade II oligodendroglioma presented with a right frontal pseudomeningocele. The patient had previously undergone two awake craniotomies for tumor resection as well as adjuvant chemoradiation. After the second resection, the patient developed wound dehiscence and infection with coagulase-negative Staphylococcus aureus requiring removal of her bone flap and repair of a cerebrospinal fluid leak. On follow-up, she had developed a large right frontal pseudomeningocele that did not respond to an initial trial of acetazolamide. Eventually, she underwent creation of a left frontal VPS with a magnetic resonance imaging-compatible adjustable shunt valve. The initial valve setting corresponded to an average pressure of $\sim 11 \mathrm{~cm} \mathrm{H}_{2} \mathrm{O}$. Initially, while inpatient, the pseudomeningocele was noted to be decreased. The patient was subsequently discharged without incident. In the interim, prior to her first postoperative visit, she underwent port placement on the ipsilateral side of the distal catheter at an outside institution. The indication for infusion port placement was the need for repeated intravenous administration of chemotherapy. It is entirely unclear why the outside surgeon chose to place the port on the same side as her recently implanted shunt.

\section{Examination}

At her first postoperative visit following shunt placement, her pseudomeningocele was noted to have reaccumulated. Due to concerns for shunt malfunction, a shunt tap was performed demonstrating ventricular catheter patency and an opening pressure of $10 \mathrm{~cm} \mathrm{H}_{2} \mathrm{O}$. Subsequently, her shunt valve was adjusted to a setting that corresponded to an average pressure of $\sim 7 \mathrm{~cm} \mathrm{H}_{2} \mathrm{O}$. Prior to a scheduled follow-up visit, her pseudomeningocele was noted to have significantly increased. The patient was admitted for shunt exploration. Preoperative imaging revealed that the port catheter crossed over the distal shunt catheter so that the shunt catheter passed between the port and clavicle. Preoperative X-ray demonstrating the relationship between the chemotherapy port and the distal shunt catheter is shown in -Fig. 1. Given the fact that the chemotherapy port placement coincided with the period in which the pseudomeningocele demonstrated enlargement and that her shunt tap demonstrated patency of her ventricular catheter, we

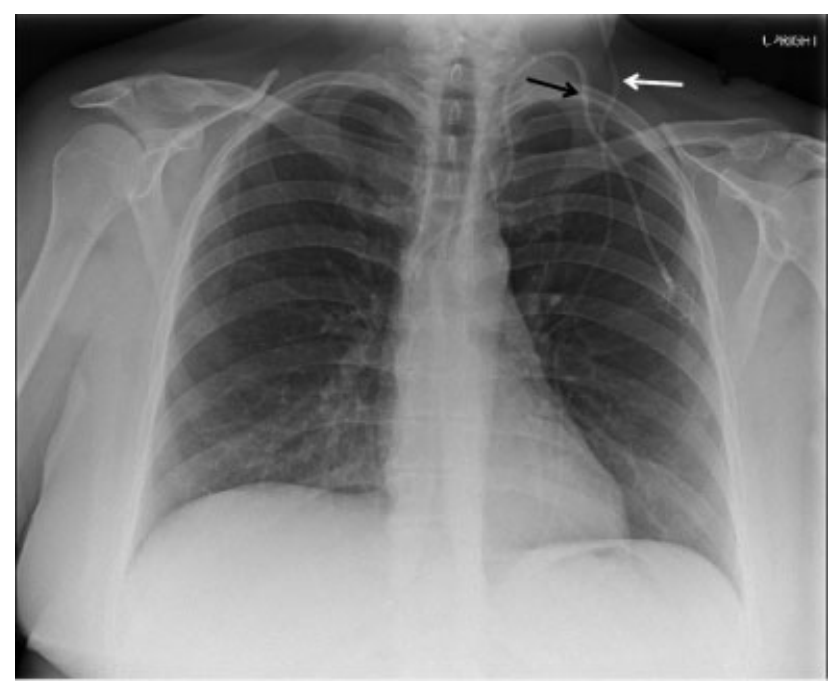

Fig. 1 Prerevision chest X-ray demonstrating crossing of chemotherapy port catheter (black arrow) and distal shunt catheter (white arrow).

hypothesized that external compression from the port may have caused an intermittent occlusion of the distal catheter.

\section{Shunt Exploration}

The patient was taken to the operating room for shunt exploration. The distal catheter was removed from the valve and connected to a manometer. When the patient's head was flat and in neutral position, the pressure was $11 \mathrm{~cm} \mathrm{H}_{2} \mathrm{O}$ (-Fig. 2) When the head was flexed and turned to the right, the pressure dropped to $3 \mathrm{~cm} \mathrm{H}_{2} \mathrm{O}$. When the patient's head was turned to the left and the manometer was reprimed, the pressure was noted to only drop to $15 \mathrm{~cm} \mathrm{H}_{2} \mathrm{O}$. This indicated position-dependent obstruction of her distal catheter. An illustration of the dynamic flow obstruction with head movement is shown in -Fig. 2 .

\section{Operation}

The prior distal catheter was removed in its entirety and a new catheter was tunneled, taking care to palpate the port catheter and cross this catheter in the soft tissue of the neck, away from the course of the port. Repeat dynamic testing with a manometer showed the pressure in the new distal catheter was less than $5 \mathrm{~cm} \mathrm{H}_{2} \mathrm{O}$ in all head and neck positions.

\section{Postoperative Course}

The patient was observed for 2 days postoperatively and showed significant reduction in the tension and size of the pseudomeningocele. Postoperative X-ray demonstrating the relationship between port and distal catheter is shown in -Fig. 3. At early follow-up, the patient demonstrated significant reduction in the size of her pseudomeningocele.

\section{Discussion}

A large retrospective multicenter study, based on UK Shunt Registry records, analyzed 10 years of epidemiological data 


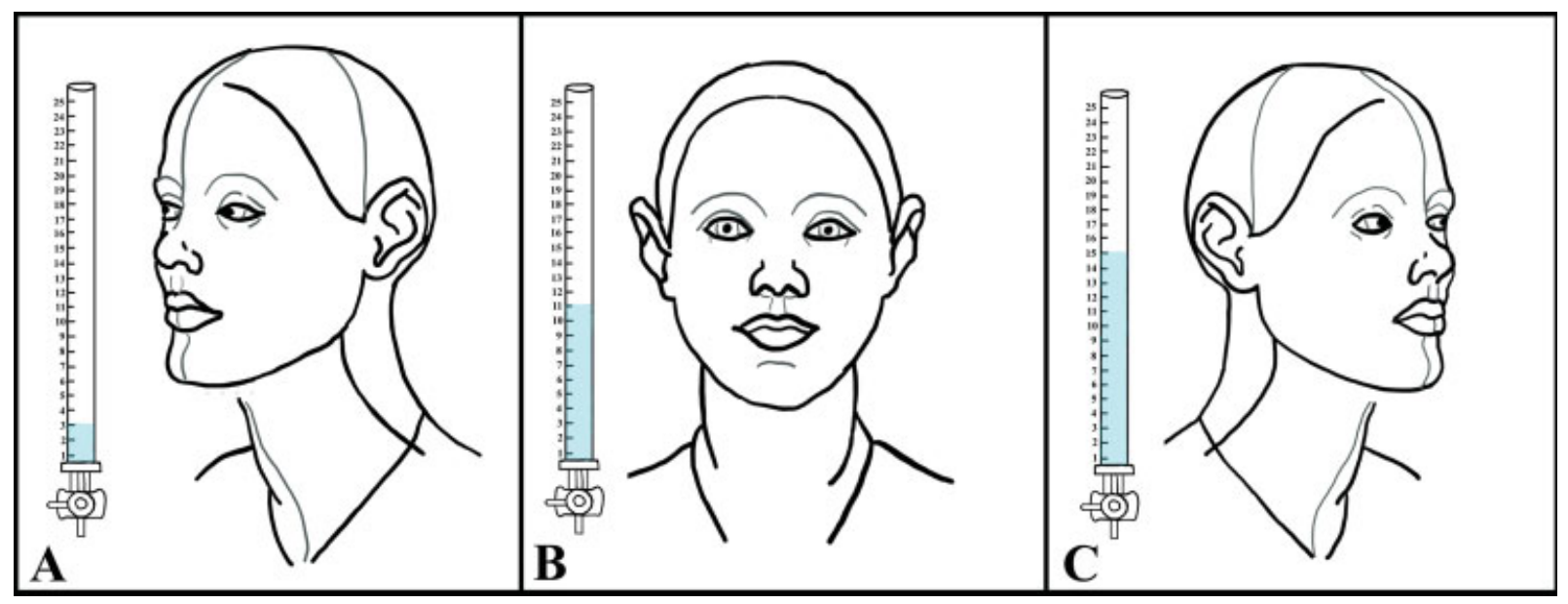

Fig. 2 Cartoon illustration of shunt exploration findings. (A) When the head was flexed and turned to the right, the pressure dropped to $3 \mathrm{~cm}$ $\mathrm{H}_{2} \mathrm{O}$. (B) When the head was flat and in neutral position, the pressure was $11 \mathrm{~cm} \mathrm{H}_{2} \mathrm{O}$. (C) When the patient's head was turned to the left and the manometer was reprimed, the pressure was noted to only drop to $15 \mathrm{~cm} \mathrm{H}_{2} \mathrm{O}$.

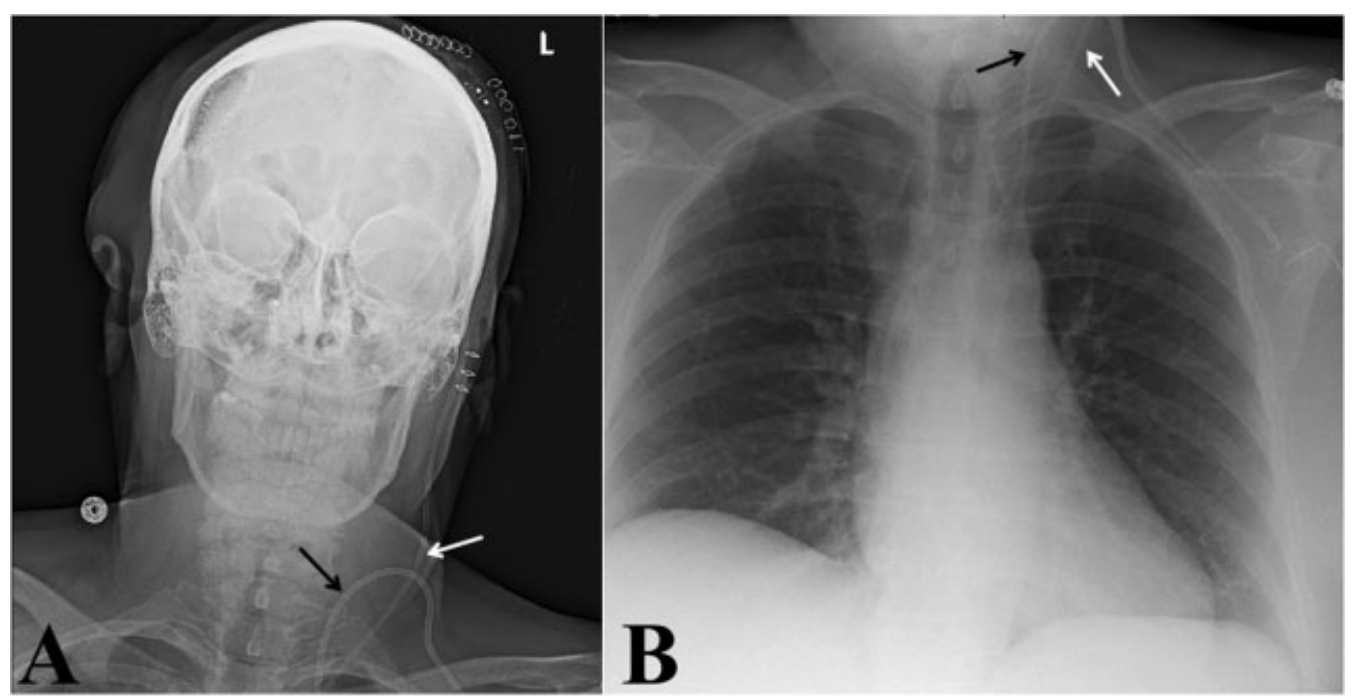

Fig. 3 Postrevision X-rays of head and neck (left) and chest (right) demonstrating relationship of chemotherapy port catheter (black arrows) and distal shunt catheter (white arrows).

for primary and revision shunting procedures performed in the United Kingdom and Ireland. ${ }^{6}$ The authors of this study identified brain tumors as the most common diagnosis necessitating primary shunt insertion in both children and adults. As the incidence of brain tumors appears to be growing, a corresponding increase in shunting procedures can be expected. ${ }^{7}$ Given the use of infusion ports in those patients requiring repeated chemotherapeutic administration or in those with otherwise difficult intravenous access, new development of clinical signs and symptoms of shunt malfunction following infusion port placement should prompt consideration for mechanical compression.

Mechanical causes of noninfectious shunt failure include obstruction, distal tubing fracture, ventricular catheter migration, and misplacement of the ventricular or distal catheter. ${ }^{8,9}$ Obstruction may occur at the level of the ventricular catheter, the shunt valve, or the distal catheter. ${ }^{8}$ The majority of distal catheter occlusions occur due to debris accumula- tion within the shunt lumen, kinking of the tubing, or terminal peritoneal obstruction by adhesions and abdominal viscera. $^{8,9}$ Though possible, we did not suspect this to be the cause of the patient's malfunction given the relatively short time from placement.

The reported case serves as a novel example of dynamic shunt malfunction due to mechanical obstruction of a distal catheter secondary to the placement of a chemotherapy port. We were concerned for obstruction when she presented with return of her pseudomeningocele following infusion port placement on the same side. Although the chest X-ray was only obtained from an anteroposterior view, the two catheters appeared to cross overlying the clavicle. Many cancer patients receive long-term infusion ports for chemotherapy or for otherwise difficult intravenous access. This case demonstrates the need for neurosurgeons recognize the possibility of interactions between shunt hardware and devices related to the nonneurosurgical aspects of cancer treatment. 
Distal catheter occlusion as seen in our case should be considered when patients present with concern for shunt malfunction following subclavian infusion port placement.

\section{Disclosures}

This research received no specific grant from any funding agency in the public, commercial, or not-for-profit sectors. There are no competing interests with regard to this project. No portion of this work has been presented or published at a prior date.

\section{References}

1 Simon TD, Riva-Cambrin J, Srivastava R, Bratton SL, Dean JM, Kestle JRHydrocephalus Clinical Research Network. Hospital care for children with hydrocephalus in the United States: utilization, charges, comorbidities, and deaths. J Neurosurg Pediatr 2008;1 (02):131-137

2 Jeng S, Gupta N, Wrensch M, Zhao S, Wu YW. Prevalence of congenital hydrocephalus in California, 1991-2000. Pediatr Neurol 2011;45(02):67-71
3 Wright Z, Larrew TW, Eskandari R. Pediatric hydrocephalus: current state of diagnosis and treatment. Pediatr Rev 2016;37(11):478-490

4 Bergsneider M, Miller C, Vespa PM, Hu X. Surgical management of adult hydrocephalus. Neurosurgery 2008;62(Suppl 2):643-659, discussion 659-660

5 Kulkarni AV, Riva-Cambrin J, Butler J, et al; Hydrocephalus Clinical Research Network. Outcomes of CSF shunting in children: comparison of Hydrocephalus Clinical Research Network cohort with historical controls: clinical article. J Neurosurg Pediatr 2013;12 (04):334-338

6 Fernández-Méndez R, Richards HK, Seeley HM, Pickard JD, Joannides AJUKSR collaborators. Current epidemiology of cerebrospinal fluid shunt surgery in the UK and Ireland (2004-2013). J Neurol Neurosurg Psychiatry 2019;90(07):747-754

7 Caldarella A, Crocetti E, Paci E. Is the incidence of brain tumors really increasing? A population-based analysis from a cancer registry. J Neurooncol 2011;104(02):589-594

8 Browd SR, Ragel BT, Gottfried ON, Kestle JR. Failure of cerebrospinal fluid shunts: part I: obstruction and mechanical failure. Pediatr Neurol 2006;34(02):83-92

9 Bates P, Rajderkar D. Common and uncommon causes of ventriculoperitoneal shunt malfunction diagnosed on plain radiographs. Curr Probl Diagn Radiol 2018;47(05):317-323 